\title{
PROJETO ÁGUA VIVA I E II: REESTRUTURAÇÃO DO SISTEMA DE SANEAMENTO AMBIENTAL DA CIDADE DE UBERABA-MG
}

\author{
Marcos Fernandes Silva ${ }^{1}$
}

Patrícia Diniz Martins ${ }^{2}$

Fernanda Brigliadori ${ }^{3}$

\begin{abstract}
RESUMO
A reestruturação do sistema de saneamento existente em Uberaba foi necessária já que o crescimento da cidade se deu de forma desordenada, sendo elaborado o Projeto Água Viva que tem como principal objetivo a melhoria da qualidade de vida da população. Esse projeto trabalha em diversos eixos, dentre eles os principais são: Drenagem das águas pluviais e fluviais, ampliação e melhoria do sistema de tratamento e abastecimento de água, ampliação e melhoria do sistema de coleta e tratamento de efluentes e educação ambiental. $O$ presente trabalho tem como objetivos apontar as medidas implementadas por este Projeto. As ações do projeto Água Viva relacionadas à drenagem urbana ocorrem na maior parte na área central e nos bairros Olinda e Universitário. As ações referentes à ampliação do sistema de coleta de efluentes são realizadas praticamente em todas as avenidas principais da cidade, substituindo a rede coletora existente por uma rede com maior capacidade de escoamento conduzindo-os até a ETE mais próxima. Já as ações referentes à ampliação e melhoria do serviço de abastecimento de água são centralizadas no sistema de tratamento de água bruta, localizada no Bairro Boa Vista. Foi realizada a ampliação da capacidade de tratamento do volume de água bruta com a construção da ETA III e otimização dos processos já realizados na ETA I e II. Na educação ambiental, são realizados eventos com os alunos da rede de educação básica e fundamental da cidade. O projeto encontra-se em execução, sendo que as últimas etapas iniciaram no mês de Maio/2014 com previsão de conclusão em Julho/2015.
\end{abstract}

PALAVRAS-CHAVE: Enchentes. Drenagem. Tratamento de Água.

\footnotetext{
${ }_{1}^{1}$ Graduando em Engenharia Ambiental, UFTM. markimfsv@hotmail.com .

${ }^{2}$ Engenharia Ambiental e MSc em Recursos Hídricos e Energéticos Ambientais pela Unicamp, e docente no curso de Engenharia Ambiental na UFTM, Patrícia_Ambiental.com.br .

${ }^{3}$ Graduanda em Engenharia Ambiental pelo ICTE-UFTM, fer.brigliadori@hotmail.com.
} 


\title{
ÁGUA VIVA I AND II PROJECT: RESTRUCTURING OF ENVIRONMENTAL SANITATION SYSTEM OF UBERABA CITY.
}

\begin{abstract}
The existent restructuring of environmental sanitation system of Uberaba was necessary because the city grow disorderly, the Project Água Viva being developed with the main objective of improve the quality of life of the population. This project works on several axes, the main ones are: drainage of rainwater and river water; expansion and improvement of treatment and water; expansion and improvement of collection and treatment of wastewater system; and environmental education of the population of the city. The actions of the Água Viva project related to urban drainage occur mostly in the central area of Uberaba, and the Olinda and the Universidade neighborhood. The actions related to the expansion of the wastewater collection system are performed on avenues in practically every major city, replacing the existing collection system with one that has greater flow capacity to drain to the nearest ETE. The actions related to the expansion and improvement of water supply services are centralized in the water treatment system, located in the Boa Vista neighborhood. With the construction of ETA III and improvements to ETA I and ETA II, the capacity of treatment of drainage water will increase. As for the environmental education, some events with students of basic and fundamental education are realized. The project is running, the latest steps being initiated in May/2014 and scheduled for completion in July/2015.
\end{abstract}

KEY-WORDS: Floods, Drainage, Water Treatment.

\section{PROYECTO DE AGUA VIVA I Y II: REESTRUCTURACIÓN DEL SISTEMA DE SANEAMIENTO AMBIENTAL DE UBERABA-MG.}

\begin{abstract}
RESUMEN
Era necesaria la reestructuración de la red de saneamiento existente en Uberaba ya que el crecimiento de la ciudad se produjo en forma desordenada, siendo preparado el Proyecto de Agua de Vida que tiene como objetivo mejorar la calidad de vida. Este proyecto trabaja en varios ejes, entre ellos los principales son: el drenaje de agua de lluvia y agua de río, ampliación y mejora del tratamiento y el agua, la expansión y la mejora de la recogida y tratamiento de aguas residuales y el sistema de suministro del sistema de la educación ambiental. Este documento tiene por objeto señalar las medidas aplicadas por este proyecto. Las acciones de proyecto Agua Viva relacionados con el drenaje urbano se producen sobre todo en la zona central y los barrios de Olinda y de la universidad. Acciones relacionadas con la expansión del sistema de recolección de aguas residuales se realizan en prácticamente todas las grandes avenidas de la ciudad, en sustitución del sistema de recogida existente para una red con mayor capacidad de flujo de conducirlos a la ETE más cercano. Ya acciones relacionadas con la ampliación y mejora del servicio de abastecimiento de agua se centralizan en el tratamiento de agua cruda, ubicada en el sistema Bairro Boa Vista. La ampliación de la capacidad de tratamiento del volumen de agua cruda con la construcción de ETA III y optimización ya realizada a ETA I y II se realizó. La educación ambiental, se realizan eventos con estudiantes de la red básica y
\end{abstract}


fundamental de la ciudad la educación. El proyecto está en marcha, y la última etapa se inició en el mes de mayo / 2014 con finalización prevista para julio / 2015.

PALABRAS-CLAVE: Inundaciones, Drenaje, Tratamiento de agua.

\section{1) INTRODUÇÃO}

A humanidade nas últimas décadas tem vivido um intenso desenvolvimento. Neste contexto, muitas cidades vieram a ter seu desenvolvimento com pouco ou nenhum planejamento, ocupando áreas impróprias para a habitação sendo na maioria das vezes próximas aos cursos de água, como foi o caso de Uberaba.

As primeiras residências foram construídas próximas às áreas onde era possível acesso fácil à água, pela inexistência de sistema público de distribuição de água. Assim o crescimento da maioria das cidades se deu próximo às áreas de vale, e com o êxodo rural presenciado na década de 70 , esse crescimento foi intensificado, dando-se uma ocupação desordenada gerando diversos problemas.

Com a população se dirigindo para os centros urbanos, as administrações públicas se viram obrigadas a buscar medidas que favorecessem o seu desenvolvimento, como impermeabilização das vias de trânsito, canalização dos corpos hídricos principalmente das áreas centrais, construções de estações de tratamento de água, sistemas de distribuição de água e de coletas de esgoto, e em algumas cidades ate estações de tratamento de esgotos, buscando se adequar a nova concepção sanitarista que surgia no país e melhor qualidade de vida.

O desenvolvimento da cidade de Uberaba se deu na Bacia do Rio Uberaba, mas precisamente na microbacia do Córrego das Lajes. Essa microbacia é composta por três córregos, que na atualidade se encontram canalizados em galerias por onde escoam as águas pluviais, fluviais e parte dos efluentes domésticos da cidade.

Como na maioria das cidades, Uberaba também teve seu crescimento sem planejamento. Na época de grande crescimento, a administração pública municipal resolveu lançar um projeto que transformava totalmente o visual das principais vias de trânsito da cidade, compostas pelas avenidas Guilherme Ferreira, Santos Dumont e Leopoldino de Oliveira, vias essas por onde os córregos escoavam. O primeiro projeto 
realizado promoveu a canalização dos rios em canais abertos e à pavimentação das faixas de trânsito dessas avenidas.

Posteriormente, esses canais foram fechados passando a serem galerias subterrâneas, sendo construída uma galeria na Avenida Santos Dumont e outra na Guilherme Ferreira e duas na Avenida Leopoldino de Oliveira, pois essa recebe o volume destas duas outras avenidas em dois pontos, onde foram construídas as caixas de confluência, conduzindo todo o volume canalizado em direção ao rio Uberaba. Essa obra teve como justificativa, a necessidade de se aumentar o número de faixas trafegáveis devido o intenso fluxo de trânsito na cidade.

Inicialmente o projeto se mostrou bastante eficiente no que se diz respeito à desobstrução do trânsito na área central, na questão paisagística e na questão sanitária, pois o esgoto era lançado antes nos canais abertos que passavam pelo centro. Com o passar do tempo e o aumento da impermeabilização da cidade aliada às chuvas começaram a aparecer os problemas com enchentes na área central, pois as galerias existentes não conseguiam escoar todo o volume que era enviado para o centro.

Como não havia separação dos efluentes domésticos das águas pluviais, nos episódios de enchentes, eles eram tragos para superfície se tornando um caso de saúde pública, pois na maioria das ocorrências o centro da cidade estava com alto número de pessoas transitando pelos passeios e pelas vias de trânsito colocando essas pessoas em contato direto com a água contaminada, disseminando doenças de veiculação hídrica.

Surge então o projeto Água Viva I e II, que foi criado para solucionar ambos os problemas pois ele trabalha com três eixos principais: Drenagem Urbana, abastecimento de água, coleta e tratamento de efluentes. Dividido em diversas etapas, o projeto ainda se encontram em fase de execução mais alguns resultados já podem ser observados.

\section{2) CARACTERIZAÇÃO DA ÁREA DE ESTUDO}


Uberaba possui atualmente uma população de aproximadamente 316.000 habitantes (IBGE 2013), sendo a oitava mais populosa do estado. Segundo dados da Administração Municipal, a cidade abrange $4.540,51 \mathrm{Km}^{2}$ de área superficial, sendo $256,00 \mathrm{Km}^{2}$ correspondentes a área urbana.

\section{1) Desenvolvimento da Cidade de Uberaba.}

A cidade de Uberaba, localizada na região do Triângulo Mineiro no estado de Minas Gerais é considerada cidade pólo na região devido ao seu potencial de desenvolvimento. As origens da cidade se deram por volta de 1809 com a fundação do 'Arraial de Uberaba' pelo então comandante Antônio Eustáquio da Silva e Oliveira e elevado a categoria de município em 1837, na época do então Príncipe Regente do Brasil Dom Pedro II (APU, 2010).

Considerada referência agrícola nacional, com um setor primário de excelência com ênfase a produção de grãos e produção de matéria prima para a produção de álcool e açúcar, é também considerada a capital mundial do Zebu sediando anualmente, a Expozebu entre os dias $1^{\circ}$ e 10 do Mês de Maio atraindo criadores de todo o mundo para Cidade.

Devido ao posicionamento geográfico estratégico e o empenho da administração pública, o setor secundário de produção de tem tido um grande desenvolvimento sendo considerado um dos 100 melhores polos industriais do Brasil (PMU, 2010). O município é considerado um dos melhores incentivadores para a instalação de empresas e indústrias nos seus três distritos industriais existentes, pois, enquanto as outras esferas da União vêm aumentando a carga de tributos, a Prefeitura Municipal de Uberaba tem dado incentivos e reduções nessa carga para servir como atrativo para que as empresas venham e instalem suas filiais na cidade (SEPLAN/PMU, 2010).

Esse processo tem se mostrado eficaz, como por exemplo, a implantação da Planta de Amônia da Estatal PETROBRÁS e a construção do Gasoduto pelo Governo Estadual de Minas Gerais. 
A cidade possui ligação com uma malha rodoviária considerável, interligando-a com as principais cidades dos estados de São Paulo, Goiás e Mato Grosso, por onde escoa boa parte da produção, que também é feito via malha ferroviária, sendo a cidade beneficiada com a Linha da Ferrovia Centro Atlântica levando os produtos de exportação para os principais portos do país.

\section{2) Urbanização da Área Central}

A área central da Uberaba passou por diversas transformações no decorrer da evolução de sua história. O crescimento acelerado e desordenado presenciado na cidade por volta de 1910 provocado pelo êxodo rural, juntamente com a falta de saneamento básico implicou em disseminação de doenças transmitidas por contato direto com água e alimentos contaminados, colocando a cidade sobre um cenário calamitoso e elevado estágio epidêmico. Não havia nenhum cuidado, não havia fossas sépticas, o esgoto fluía junto com os córregos pelas próprias ruas, como pode ser visualizado na Figura 01. Hoje, neste local, localiza-se o Mercado Municipal.

$\mathrm{Na}$ década de 1920, por pressão populacional juntamente com a nova concepção sanitarista que surgia, a Câmara Municipal atendendo aos clamores públicos contrata o então Engenheiro Sanitarista Saturnino de Brito para elaborar um projeto que readequasse o centro da cidade e colocasse fim ao caos vivido e a crise epidemiológica da época.

O projeto ficou conhecido como "Saneamento e Planta de Expansão de Uberaba”. O projeto previa a canalização dos córregos existentes na cidade que funcionavam como drenos naturais, coletores de águas pluviais e ao mesmo tempo, oferecia condições para o saneamento da cidade. 
Figura 01: Avenida Leopoldino de Oliveira na década de 1910.

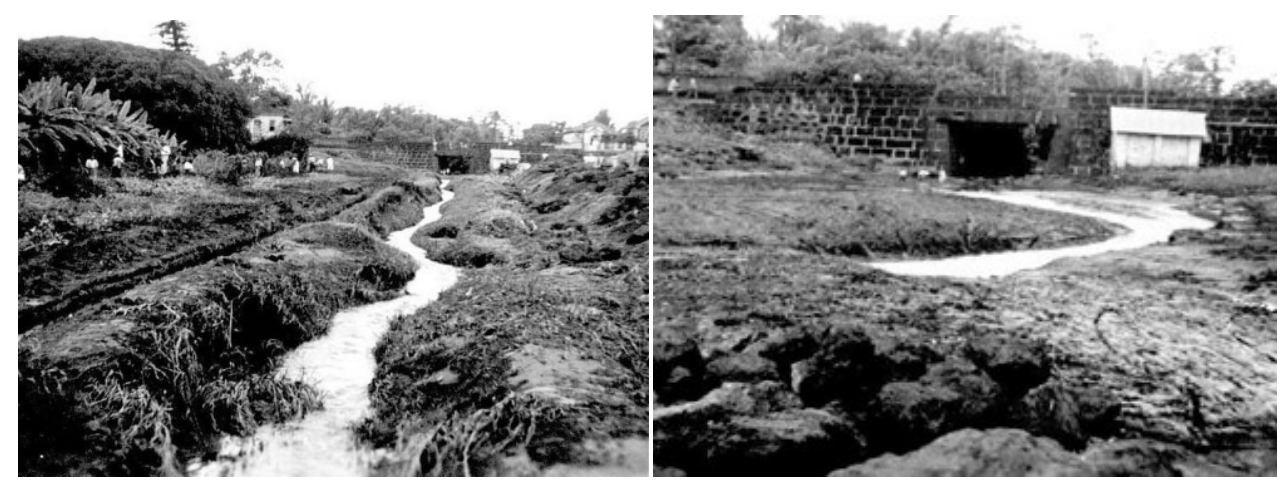

Fonte: Arquivo Público de Uberaba (APU).

A elaboração e entrega do projeto ocorreu em 1922 à Câmara Municipal, que previa a canalização dos córregos na Avenida Leopoldino de Oliveira e Guilherme Ferreira, mas as obras só foram iniciadas em 1937, dando uma nova perspectiva a cidade como pode ser visualizado nas Figuras 02 e 03.

Figura 02: Avenida Leopoldino de Oliveira década de 1950.

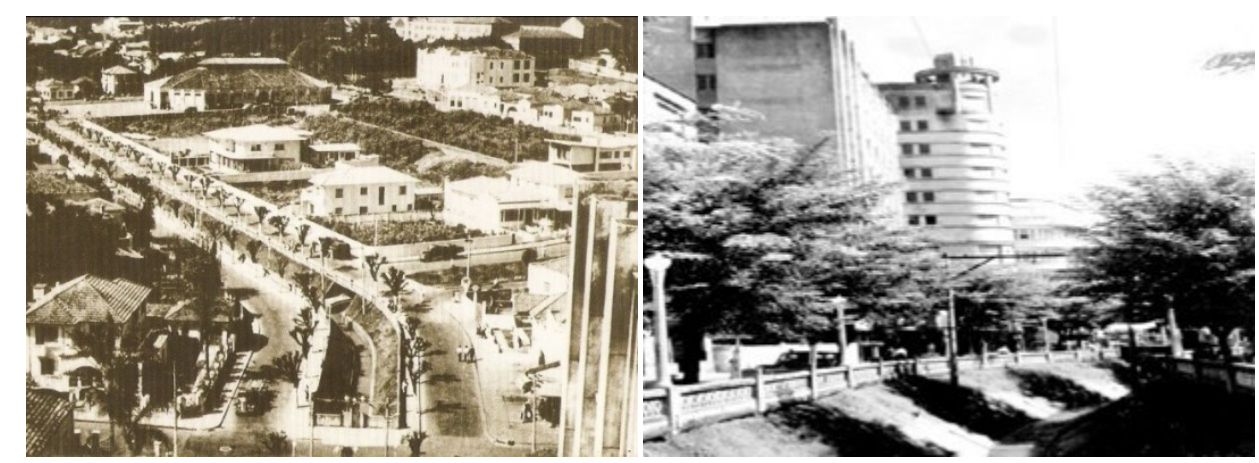

Fonte: Arquivo Público de Uberaba (APU) 
Figura 03: Avenida Guilherme Ferreira de 1960

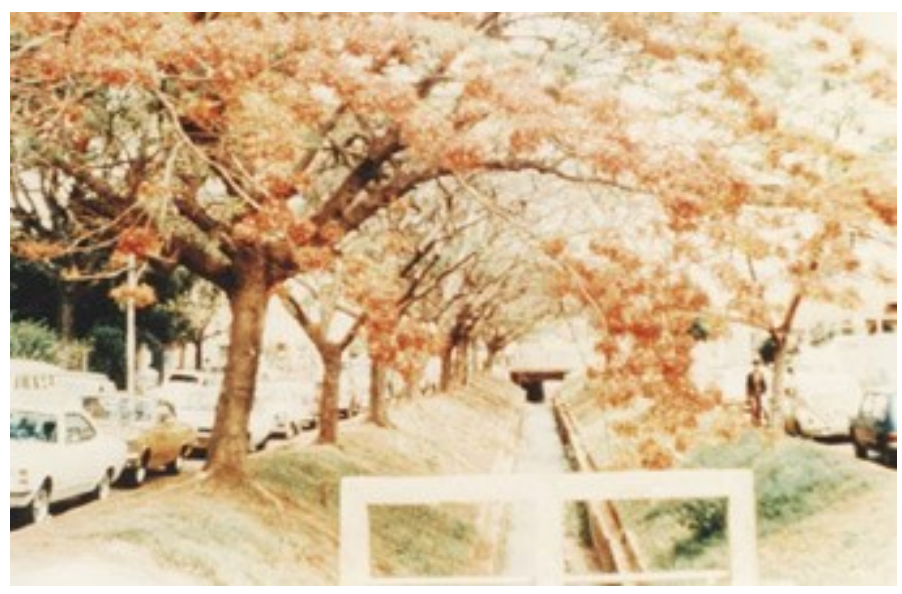

Fonte: Arquivo Público de Uberaba (APU)

Com a canalização dos córregos e a implantação do sistema de coleta de esgotos, muitas doenças foram controladas e a qualidade de vida na população melhorou. Porém, os córregos canalizados recebiam juntamente as águas pluviais e os efluentes domésticos o que ocasionava odor desagradável na área central. Foi então que a Sociedade de Engenharia de Uberaba propôs a substituição dos canais por galerias subterrâneas para dar solução a dois problemas: o odor desagradável na área e o crescente fluxo de veículos.

Executado o projeto em 1970, a área central da cidade passa a ter um aspecto totalmente renovado e moderno, dando maior fluxo aos veículos e tendo poucas modificações significativas de seu design nos dias atuais (PMU). O que não se esperava é que as galerias construídas não fossem conseguir escoar toda a vazão de pico que chegava na área central, passando esta a sofrer frequentes inundações como pode ser observado na Figura 04. 
Figura 04: Avenida Leopoldino de Oliveira, na esquerda. Na direita sobre efeito das enchentes.

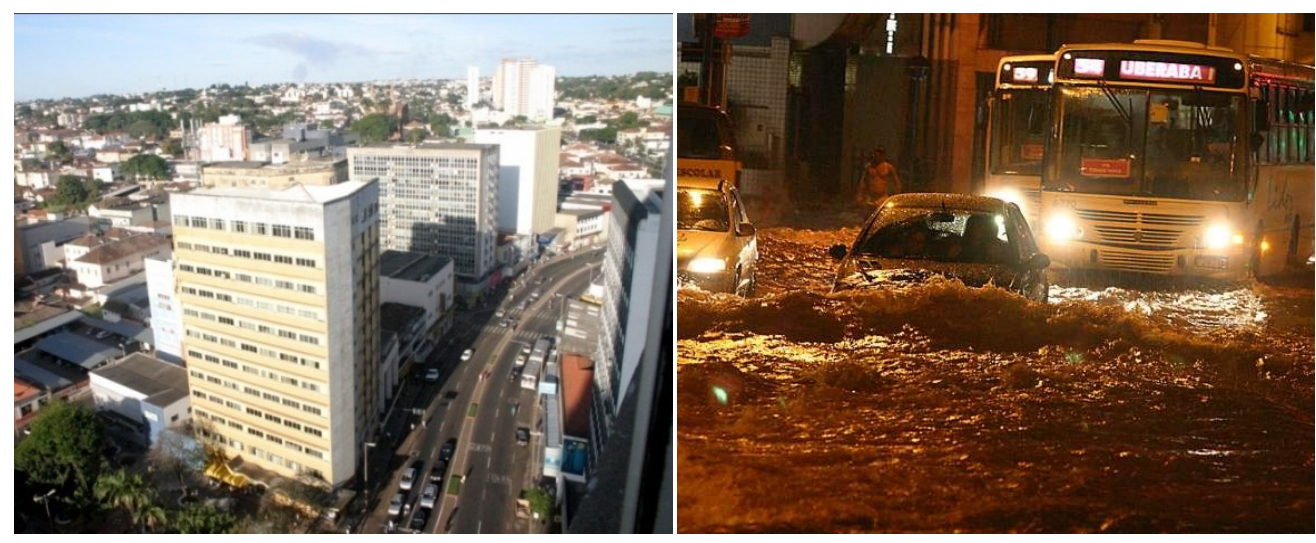

Fonte: Arquivo Público de Uberaba (APU)

Com o problema das Enchentes que assolava a população frequentemente, a Prefeitura Municipal decide buscar uma solução para esse e outros problemas relacionados com o projeto Água Viva.

\section{3) PROJETO ÁGUA VIVA I E II}

O Projeto Água Viva tem como principal objetivo à melhora da qualidade de vida da população urbana, rural e das cidades que dependem das águas da bacia do Rio Uberaba. Suas principais ações são voltadas para o problema das enchentes na área central, a degradação dos corpos hídricos causadas pelo o lançamento de efluentes in natura, e ampliação do tratamento da água atendendo a demanda da população.

Composto por diversos eixos de atuação, o projeto tem um maior empenho em dois eixos, sendo a drenagem urbana e tratamento de água e esgoto.

\section{1) Macrodrenagem e Microdrenagem}

O projeto propôs a ampliação do sistema de drenagem feito pelas galerias já existentes nas avenidas principais da cidade, construindo novas galerias em algumas 
das avenidas e ampliando as existentes em outras. Segundo o CODAU, a capacidade de escoamento realizada pelo sistema de drenagem sofrerá um aumento de $100 \%$, diminuindo os riscos de enchentes na área central.

Alguns registros fotográficos feitos durante a execução da macrodrenagem nas vias principais podem ser visualizados nas Figura 05, 06 e 07.

Figura 05: Obras de drenagem na Avenida Leopoldino de Oliveira (09/2011).
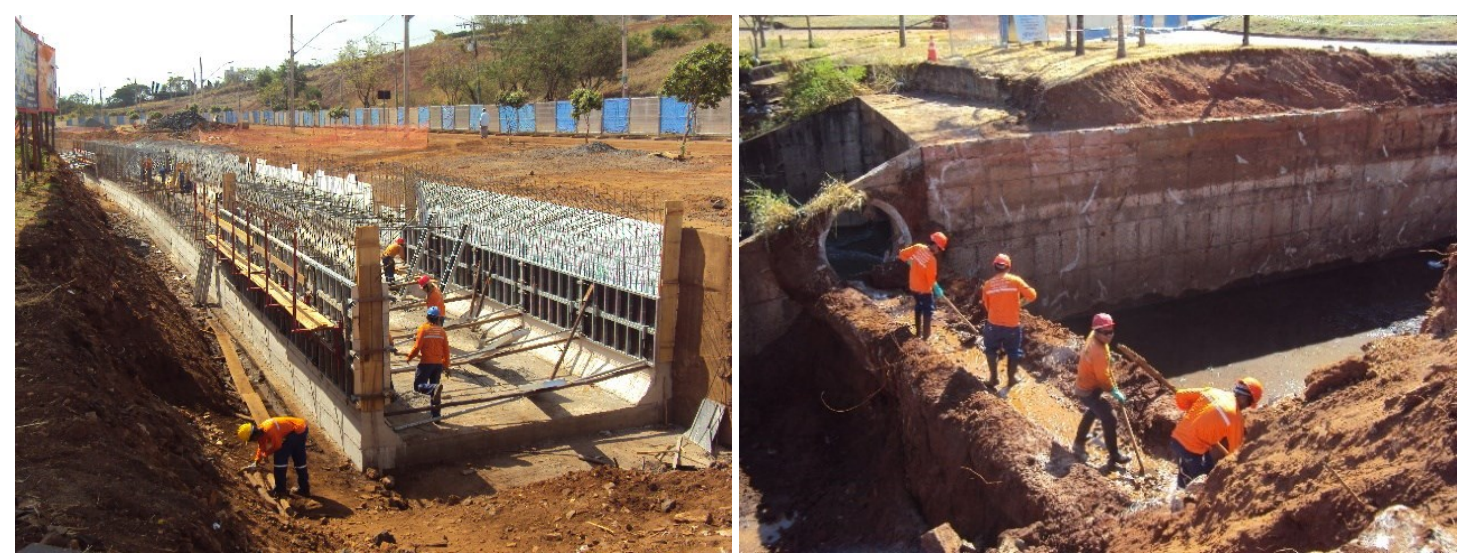

Fonte: PMU.

Figura 06: Obras de drenagem na Avenida Leopoldino de Oliveira (09/2011).

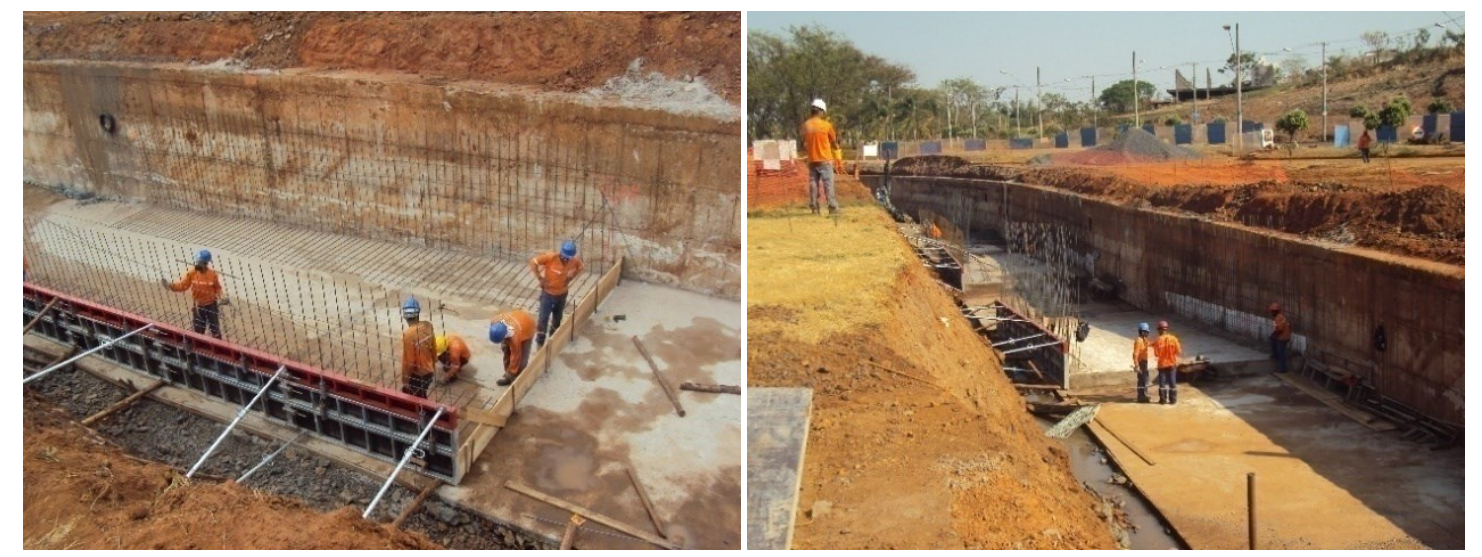

Fonte: PMU. 
Figura 07: Obras de drenagem no bairro Universitário e Olinda (05/2011).

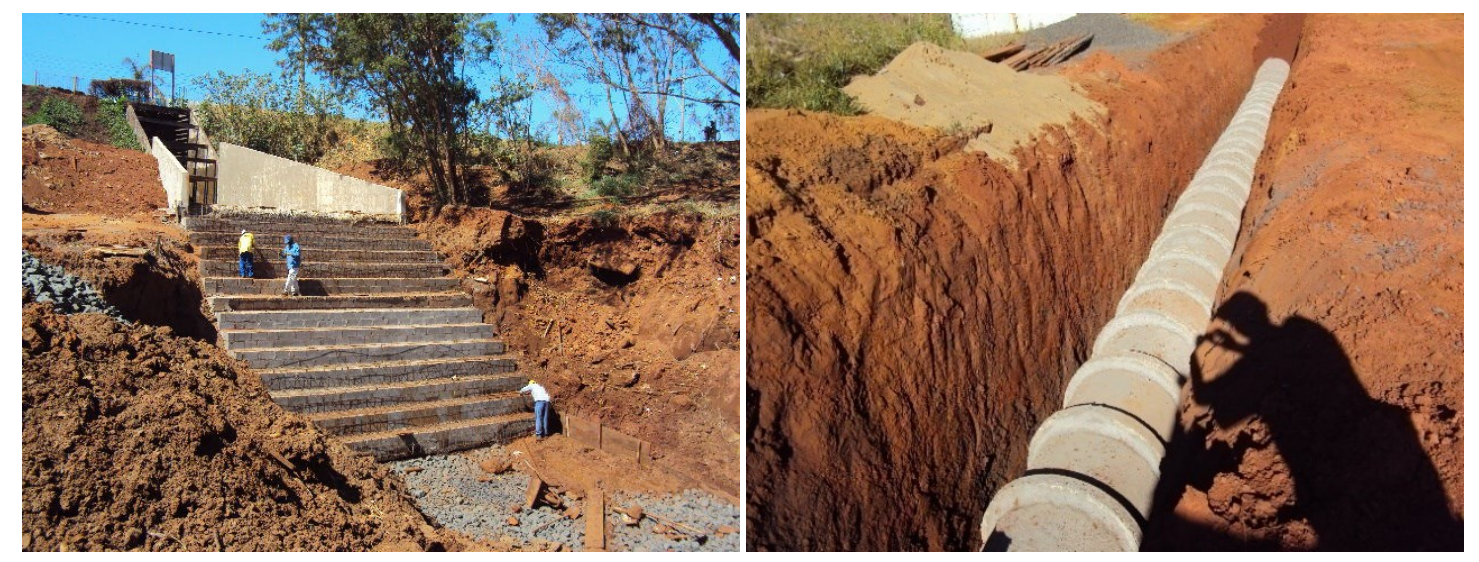

Fonte: PMU.

O processo de construção e ampliação do sistema de drenagem urbana se encontra quase concluído, sendo que no mês de maio iniciou-se a terceira etapa de macrodrenagem referente à ampliação das galerias das Avenidas Santos Dumont e Santa Beatriz. Essa etapa conta com recursos da ordem de $\mathrm{R} \$ 11.000 .000,00$ para execução por parte da PMU e outros R\$ 29.000.000,00 por parte do Ministério das Cidades.

Com conclusão da ampliação do sistema de drenagem urbana existente é esperado que as vazões de pico que chegam à área possam ser amortizadas e assim diminuindo os transtornos causados pelas enchentes na cidade de Uberaba.

\section{2) Abastecimento e tratamento de água}

Os serviços de fornecimento de água tratada, segundo dados da administração Municipal de Uberaba, tem uma cobertura de aproximadamente $98 \%$ da população total da cidade, sendo o referido serviço executado pelo Centro Operacional de Desenvolvimento e Saneamento de Uberaba (CODAU, 2010).

Atualmente a captação ocorre no Rio Uberaba e a água é bombeada para o centro de tratamento de água localizado no Bairro Boa Vista. No local existem duas ETA's que estão operando com máxima capacidade (Figura 08-A). Com o sistema de 
tratamento funcionando sobre pressão e não conseguindo mais atender a demanda solicitada pela população, o projeto Água Viva propôs a reforma e ampliação do atual sistema de tratamento, construção de uma terceira ETA (Figura 08-B), e modernização das duas existentes, o que eleva a capacidade de produção do sistema como um todo e melhora a qualidade do serviço prestado para população. $O$ valor total das obras está estimado em aproximadamente $R \$ 50.000 .000,00$ milhões (PMU, 2011) provenientes do Programa de Aceleração do Crescimento (PAC II), sendo que as obras estão em execução desde outubro de 2011.

Figura 08: A- Sistema de tratamento de água antes da reforma; B- Configuração do sistema de água após as obras de reforma e ampliação.

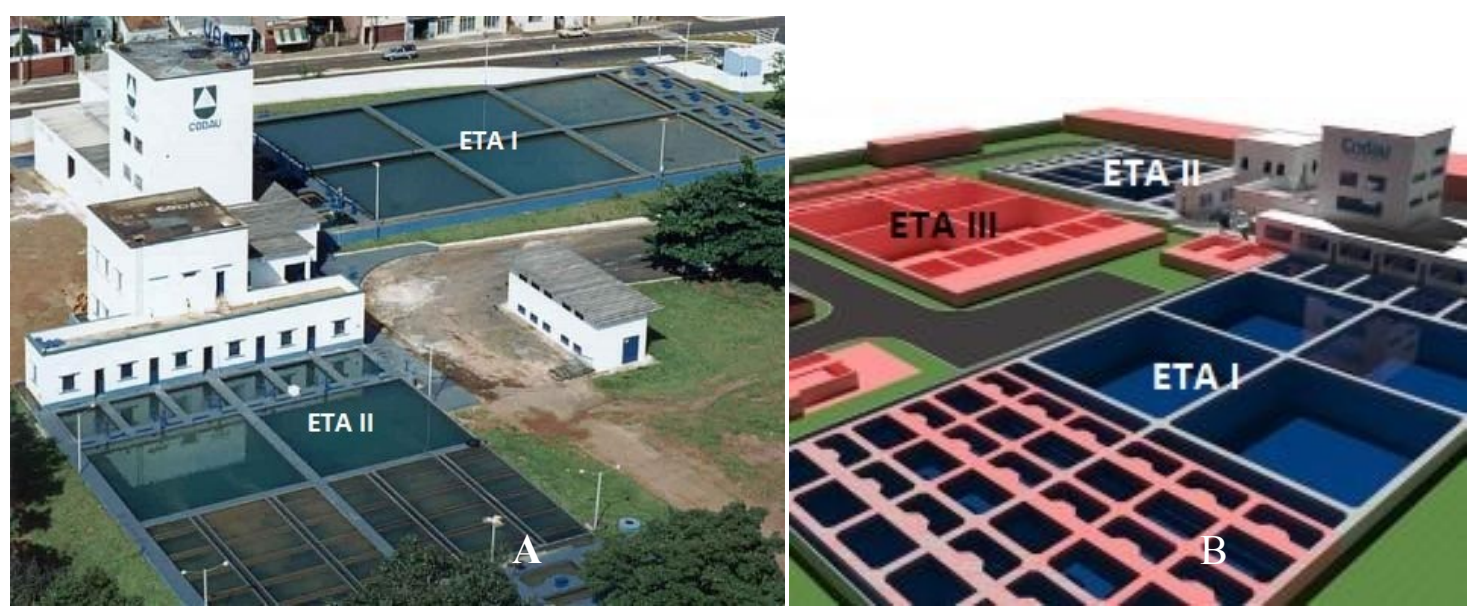

Fonte: CODAU

Após a entrada em operação da ETA III, reforma da ETA I que foi construída em 1940 e reforma da ETA II, construída na década de 70, o complexo sairá da capacidade de tratamento de água dos atuais $900 \mathrm{~L} / \mathrm{s}$ para $1.700 \mathrm{~L} / \mathrm{s}$ (PMU). $\mathrm{O}$ rio Uberaba em determinadas épocas do ano não consegue abastecer com segurança a demanda, pois fornece apenas a capacidade atual de processamento da ETA I e II em operação.

Como solução desse problema, em paralelo com o projeto água viva, existe o Projeto de "Transposição do Rio Claro", no qual o CODAU conseguiu outorga de captação de um volume de $800 \mathrm{~L} / \mathrm{s}$ por meio de adutoras para o sistema de abastecimento de Uberaba. O projeto é alvo de intensas críticas por parte de 
produtores que vivem na bacia do Rio Claro, com medo que a essa captação venha a prejudicar a produção agrícola no local. O sistema de adutoras terá aproximadamente $35 \mathrm{~km}$, funcionando pelo sistema motor bomba num percurso de 2,3 $\mathrm{km}$ até um reservatório, e depois irá por escoamento livre até o bairro Boa vista, onde ficam localizado as ETA I,II e III.

$\mathrm{Na}$ busca pela melhoria da qualidade do serviço prestada à população, o setor de licitação do CODAU lançou no início do ano de 2013, edital para contratação de empresa especializada na construção de adutoras para realizar as obras entre a ETA e os bairros Olinda e Universitário. A obra possui recursos da ordem de R\$ $4.400 .000,00$ e uma extensão de 11,0 km (Figura 09) e tem como objetivo a redução da ocorrência de interrupção no fornecimento de água para a população que lá reside, sendo esse um problema constante principalmente na época de estiagem, onde as vazões do Rio Uberaba diminuem consideravelmente sobrecarregando o sistema de distribuição.

Figura 09: Percurso da nova adutora entre a ETA e o Centro de Reservação (CR) VI.

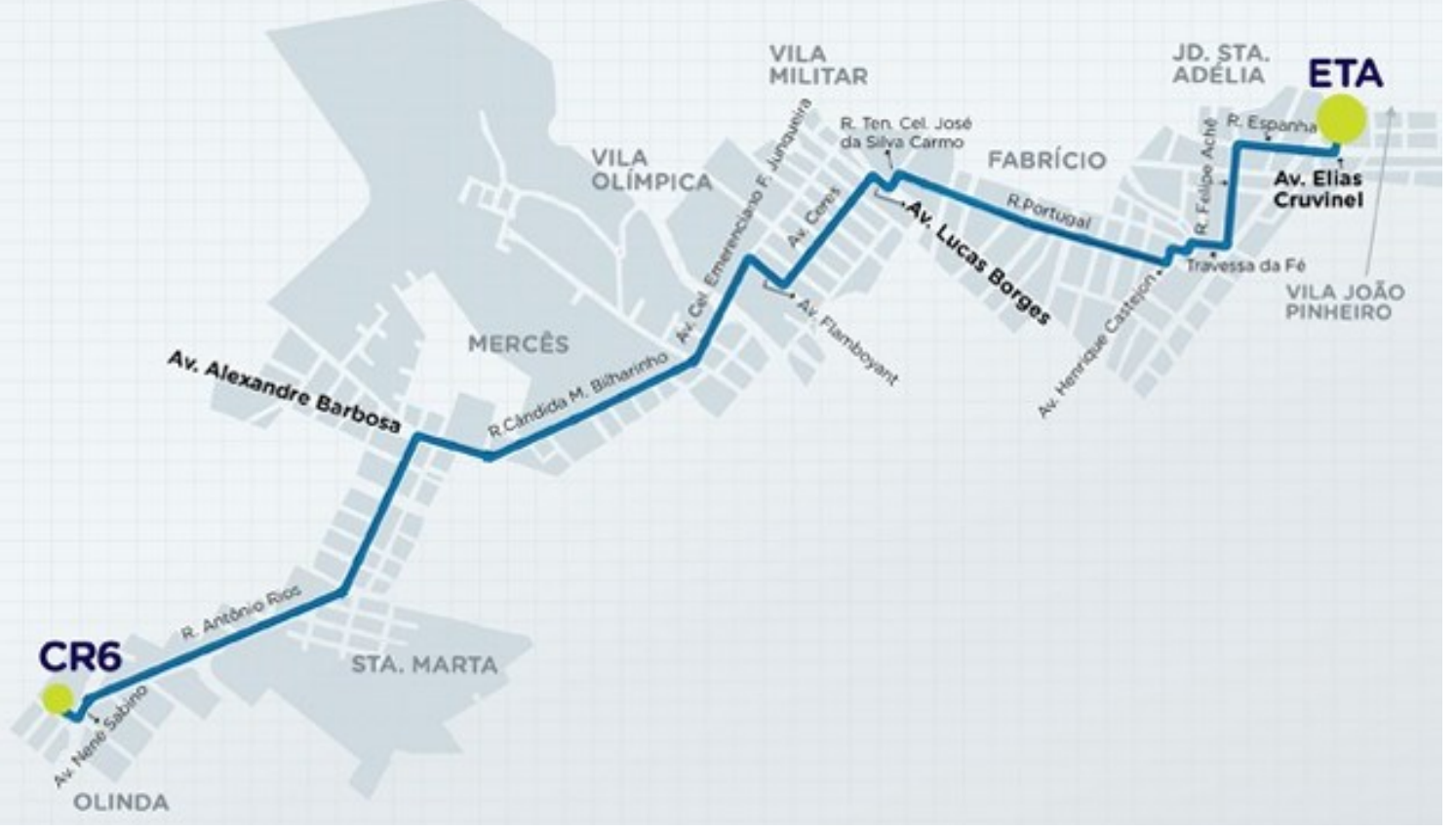

Fonte: CODAU 


\section{3) Sistema de coleta e tratamento de Esgoto}

O serviço de coleta de esgotamento sanitário da cidade hoje possui uma abrangência do serviço de cerca de 100\%, segundo dados da administração municipal, sendo que $72 \%$ desse volume coletado é tratado pelo CODAU. A ETE é considerada uma referência estadual de qualidade de tratamento, com níveis muito bons de redução da carga orgânica que chega ao sistema de tratamento em operação.

O sistema de tratamento possui duas ETE's, a ETE - Francisco Veludo, em operação, com capacidade para tratar $74 \%$ dos efluentes coletados e a ETE Filomena Cartafina, que atende uma população de aproximadamente 3.000 habitantes, tratando cerca de $2 \%$ do volume total de efluentes da cidade. Uma terceira estação, a ETE - Conquistinha se encontra em fase de conclusão das obras com capacidade de tratamento estimado em $22 \%$ do volume total. Esse volume a ser tratado corresponde ao volume coletado na área de expansão da cidade e lançados in natura no Ribeirão Conquistinha. Quando as três estiverem em funcionamento, a cidade de Uberaba terá $98 \%$ dos efluentes gerados sendo tratados.

A ETE Francisco Veludo (Figura 10) que está em operação fica localizada no bairro Alfredo Freire, e consta com o sistema de tratamento dos efluentes e uma central de tratamento do Lodo resultante do processo, e possui estimativa de remoção da DBO de entrada no sistema de $70 \%$ e com horizonte de evolução para $93 \%$.

Figura 10: ETE Francisco Veludo.

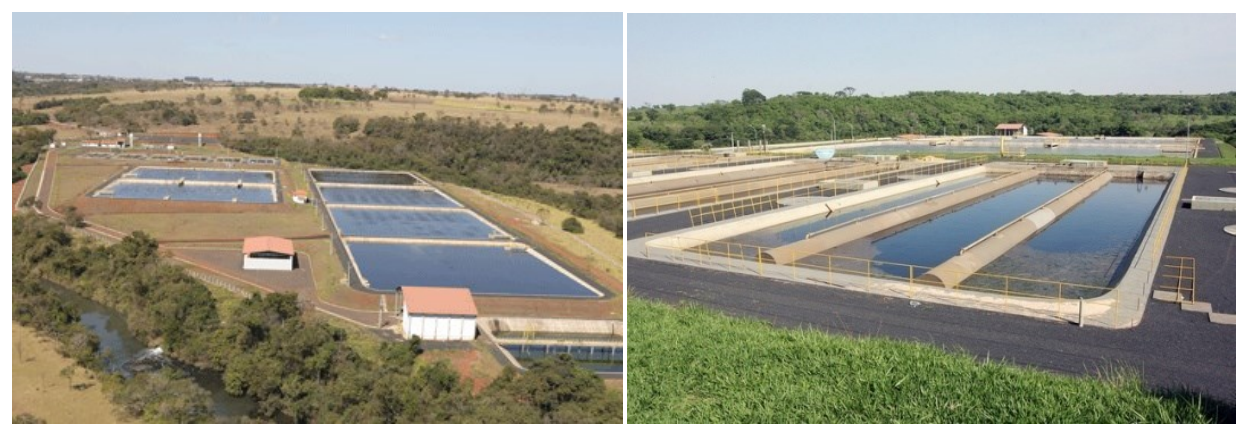

Fonte: CODAU 
A ETE - Filomena Cartafina (Figura 11) fica localizada no bairro Filomena Cartafina e trata seu efluente por meio da absorção da materia orgânica dos efluentes por uma especie de capim, daí se originou seu nome popular de ETE - CAPIM. Após o tratamento com eficiencia de remoção de 95\% (CODAU), ocorre o seu despejo no Ribeirão Conquistinha. Em 2012 foi licitado uma obra de modernização dessa ETE, passando sua capacidade de tratamento de efluentes para atender uma população de aproximadamente 20.000 habitantes.

Figura 11: ETE Filomena Cartafina.

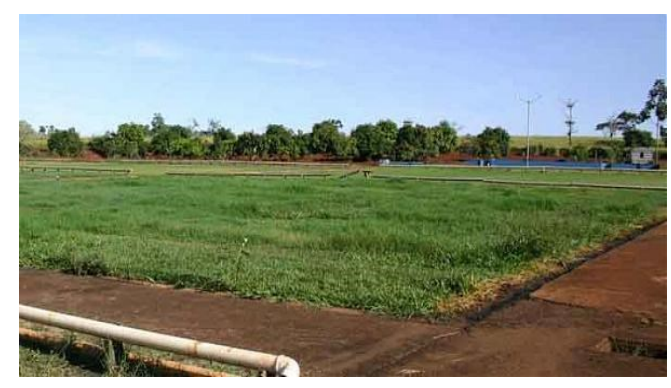

Fonte: CODAU

A ETE Conquistinha (Figura 12) se encontra em fase de acabamento é também parte do projeto Água Viva, que além da construção desta ETE, prevê também a construção dos interceptores de esgoto.

Figura 12: ETE Conquistinha

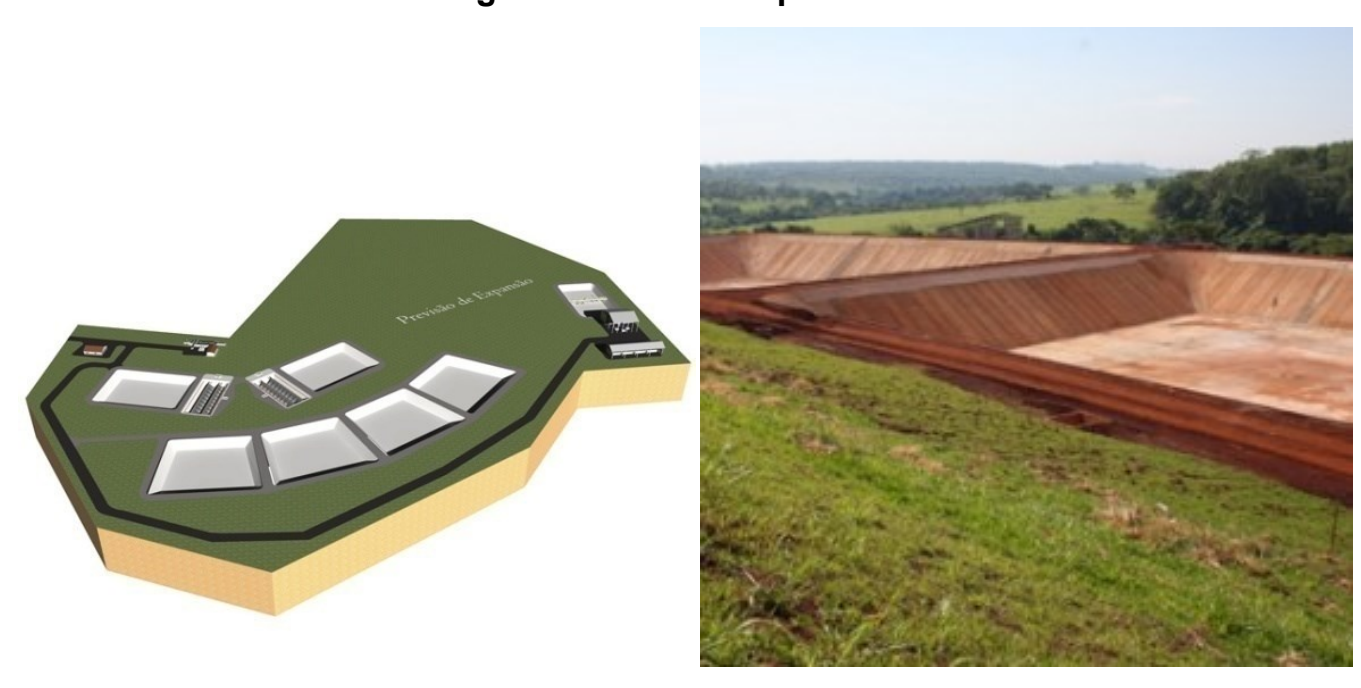

Fonte: CODAU 
Atualmente, em alguns pontos da área central os efluentes não são separados das águas fluviais e pluviais nas galerias de drenagem, sendo o volume não captado pelo sistema coletor existente despejado in natura na bacia do Córrego das Lajes e conduzido para o Rio Uberaba. A expansão do sistema coletor ocorre com a implantação de tubos coletores ao lado das galerias de drenagem, separando os efluentes domésticos das águas pluviais e fluviais drenadas.

O projeto prevê a separação total do efluente das águas fluviais e o tratamento de $98 \%$ de todo o esgoto coletado, evitando que a alta carga orgânica chegue ate os corpos hídricos, melhorando assim a qualidade das águas da Bacia do Rio Uberaba.

\section{4) CONSIDERAÇÕES FINAIS}

A cidade de Uberaba, com esse projeto de reestruturação do sistema de saneamento ambiental adota um modelo de gestão ambiental bastante eficaz, gerando um desenvolvimento elevado da economia e se preocupando com o meio ambiente.

Obras de reestruturação precisam da viabilização de um grande montante de verbas para execução, além de impor diversos transtornos à população durante sua execução. Porém é necessário ponderar que tais obras trazem muitos benefícios como melhoria da qualidade e ampliação dos serviços prestados. Como tentativa de minimizar essa visão de que as obras apenas geram transtornos, o CODAU lançou uma campanha publicitária durante as obras na área central com o tema: "Os transtornos são temporários, os benefícios são permanentes" e foram colocados nas vias de trânsito da cidade.

Além de benefícios diretos, ocorrem também os indiretos como, por exemplo, o aumento da atratividade de indústrias do terceiro setor para a cidade. Tais complexos industriais para se instalarem em uma cidade precisam da certeza de que suas necessidades básicas como fornecimento de energia elétrica, infraestrutura de transporte, fornecimento de água e coleta de esgotos podem ser atendidos com qualidade pelo serviço público garantindo a sua produtividade. 
Uma cidade que possui um sistema de saneamento ambiental bem estruturado é propícia a receber grandes montantes de investimentos advindas do setor privado e público. Segundo a Prefeitura Municipal de Uberaba, um dos fatores que levaram a gerência executiva da Estatal PETROBRAS a agilizar o processo de análise de viabilização da implantação da planta de amônia na cidade, com investimentos da ordem de dois bilhões de reais, foi relacionado com o posicionamento geográfico estratégico que a cidade possui e devido às obras de reestruturação de todo sistema de saneamento ambiental. Além da instalação desse complexo industrial que irá produzir amônia, ocorrerá também a implantação do Gasoduto Betim-Uberaba, proporcionando também as indústrias já instaladas na cidade, meios de se desenvolverem.

Desde o início da execução das obras do projeto Água Viva vários benefícios já foram notados como o maior controle das enchentes na área central realizado pelas obras de drenagem urbana, maior oferta de água tratada. Em termos de benefícios financeiros diretos, o CODAU recebeu o prêmio do Programa de Despoluição de Bacias Hidrográficas (Prodes), do Ministério do Meio Ambiente, por meio da Agência Nacional das Águas (ANA) somando um valor de $\mathrm{R} \$ 8.150 .000,00$ pela qualidade da ETE - Francisco Veludo.

Além dos benefícios financeiros e sociais, a reestruturação do sistema de saneamento ambiental proporciona a recuperação e a valorização do meio ambiente natural como elemento fundamental da estratégia de controle da poluição das águas. A retirada dos lançamentos in natura nos mananciais e ainda o tratamento em nível adequado destes efluentes, promoverá um ganho relevante na qualidade das águas do Rio Uberaba, não afetando as futuras captações a serem feitas a jusante da cidade de Uberaba.

\section{REFERÊNCIAS}

APU. HISTÓRIA E EVOLUÇÃO DE UBERABA Disponível em: <http://www.uberaba.mg.gov.br/apu>. Acesso em: 10 maio 2014. 
CODAU. DADOS DO PROJETO ÁGUA VIVA. 2013. Disponível em:

<http://serv1.codau.com.br:8080/noticiaDetalhe.php?codigo=225000047>. Acesso em: 11 maio 2014.

JORNAL DA CIDADE. CMU APROVA FINANCIAMENTO PARA O PROJETO

ÁGUA VIVA. 2013. Disponível em: <http://www.jcuberaba.com.br/cidade/geral/202/cmu-aprovafinanciamento-para-o-projeto-gua-viva/>. Acesso em: 11 maio 2014.

PREFEITURA MUNICIPAL DE UBERABA (PMU). PROJETO ÁGUA VIVA. 2012. Disponível em: <http://www.uberaba.mg.gov.br/portal/conteudo,8526>. Acesso em: 10 maio 2014.

PREFEITURA MUNICIPAL DE UBERABA (PMU). UBERABA EM DADOS. 2009. Disponível em: <http://www.uberaba.mg.gov.br/portal/conteudo,232>. Acesso em: 11 maio 2014.

PREFEITURA MUNICIPAL DE UBERABA (PMU). GALERIA DE FOTOS PROJETO ÁGUA VIVA.

Disponível em: < http://www.uberaba.mg.gov.br/portal/galeriaimagens,agua_viva,galeria\#>. Acesso em: 11 maio 2014. 